\title{
An Ergonomic Assessment Of Four Different Donor Nephrectomy Approaches For The Surgeons And Their Assistants
}

This article was published in the following Dove Press journal: Research and Reports in Urology

\section{Baptiste Marçon (D) Willy Ngueyon Sime ${ }^{2}$ \\ Francis Guillemin ${ }^{2}$ \\ Nicolas Hubert ${ }^{\prime}$ \\ François Lagrange' \\ Céline Huselstein ${ }^{3}$ \\ Jacques Hubert ${ }^{1,4}$}

'Department of Urology, University Hospital Nancy-Brabois, Vandœuvre-lèsNancy, Nancy 545I I, France; ${ }^{2}$ Clinical Epidemiology Center Inserm CIC-EC 1433, University Hospital Nancy-Brabois, Vandœuvre-lès-Nancy, Nancy 54505, France; ${ }^{3}$ Department of Health Sciences and Engineering, Faculty of Medicine, Lorraine University, Nancy, France; ${ }^{4}$ IADI-UL-INSERM (UI254), University Hospital Nancy-Brabois, Vandœuvre-lèsNancy, Nancy 545 I I, France
Correspondence: Baptiste Marçon Department of Urology, University Hospital Nancy-Brabois, Allée du Morvan, Vandœuvre-lès-Nancy, Nancy 545II, France

Tel +33067508860l

Email baptistemarcon@orange.fr
Introduction: Open surgery is increasingly being replaced by laparoscopic approaches that are more demanding for the surgical team. The physical and mental workload of these approaches have not been quantified.

Materials and methods: A multicenter prospective study was performed evaluating the physical and mental stresses of 4 surgical approaches (open surgery [OS], standard laparoscopy [SL], hand-assisted laparoscopy [HAL], and robot-assisted laparoscopy [RAL]) for donor nephrectomy for the surgeon and their assistant. The Borg Scale was used to evaluate exertion in different body parts every 30 mins during surgery and the NASA-TLX score was used to evaluate overall workload.

Results: 264 nephrectomies were performed over a 33-month period and 258 questionnaires evaluating these surgeries were obtained. Surgeons experienced less left shoulder and arm exertion and left forearm and hand exertion, but greater lower back exertion, as measured by the Borg scale, with RAL. Leg exertion was significantly greater with OS. Assistant surgeons experienced increased exertion in the back, right shoulder and arm, and right forearm and hand with RAL. NASA Task load index (TLX) surgeon scores showed mental demand was similar for all 4 surgical approaches. Physical demand was lower and overall performance was higher with RAL.

Discussion: Four different nephrectomy surgical approaches were evaluated in a multicenter setting. Surgeon and assistant scores of physical exertions were generally in the "easy" range but confirmed that robotic surgery is an ergonomic progress compared to other techniques, except for the axial skeleton. Further, it degrades the working conditions for the assistant. Keywords: ergonomics, surgery, nephrectomy, laparoscopy, robot, bed-side assistant, living donor

\section{Introduction}

Discomfort related to body position is a well-known occurrence with open surgery. Additional stresses have been introduced with the development and widespread acceptance of laparoscopic surgery. ${ }^{1}$ Laparoscopy requires twisting of the body, sometimes with extreme flexion and extension of the arms (Figure 1), as the surgeon operates through the trocars in their stationary position. It has been estimated that surgeons have to exert 6 or 7 times more effort with laparoscopy than with open surgery to perform the same task. ${ }^{2}$ Back and upper limb pain in surgeons performing conventional laparoscopy is a common occurrence. ${ }^{1,3}$

Pain has been reported more frequently with laparoscopic surgery than with robotic surgery ${ }^{4}$ (Figure 2) and more frequently in surgeons that perform more 


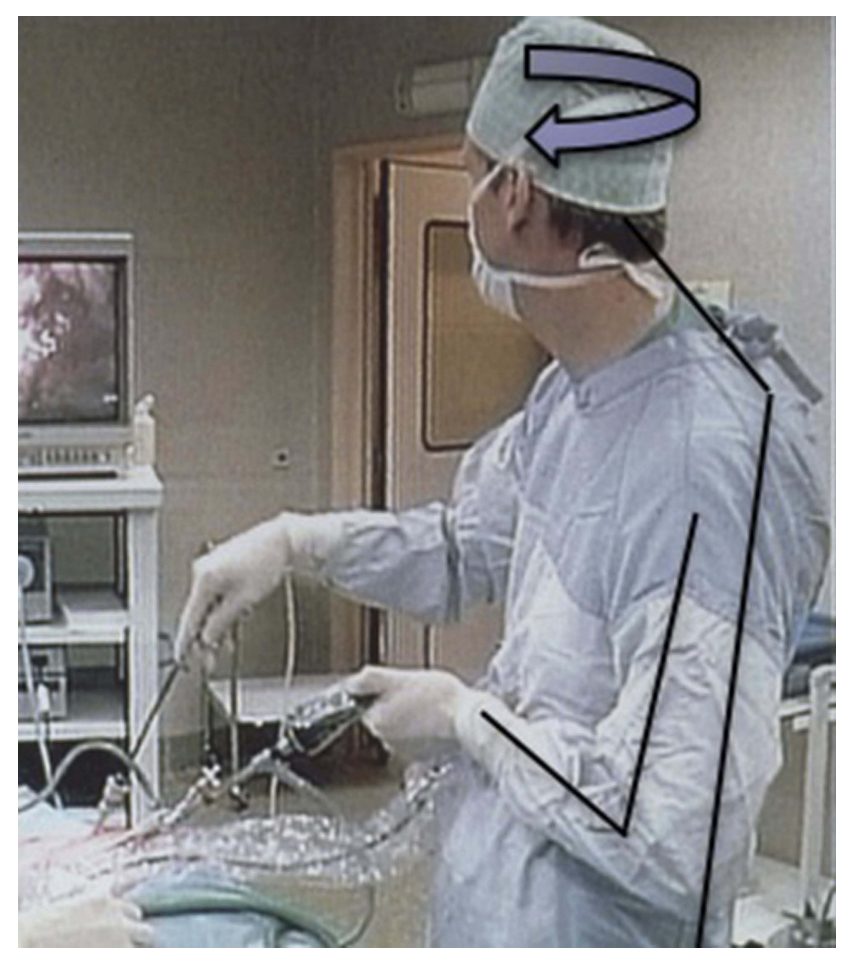

Figure I Arm and neck stresses for the surgeon performing standard laparoscopy.

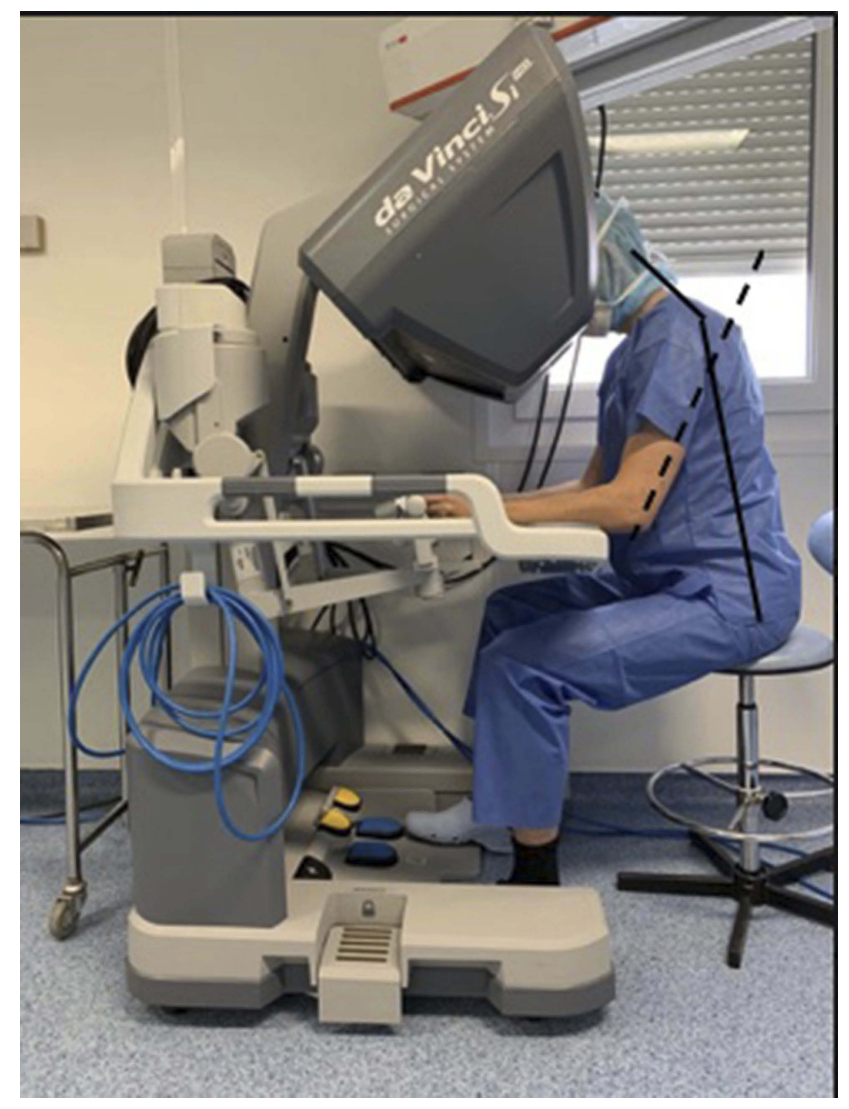

Figure 2 Neck and shoulder stresses for the surgeon performing robot-assisted laparoscopy. advanced surgical approaches than in those that do not. ${ }^{5}$ Surgical assistants also experience ergonomic stresses, which may be different from those of the surgeon. It is generally assumed these are less intense than those of the surgeon, but they have seldom been measured. ${ }^{6}$

While laparoscopic surgery is better tolerated by patients, it causes more musculoskeletal problems for surgeons. ${ }^{7}$ No study has evaluated and compared the physical and mental demand involved in all 4 operative approaches for a surgery in both the surgeon and their assistant. We performed a multicenter prospective study to better understand the physical and mental constraints associated with nephrectomy.

\section{Materials And Methods}

"DOVIREIN" a multi-center, parallel-group, non-randomized prospective survey compared medical economic and quality of life data of four surgical donor nephrectomy approaches, over a 33-month period (from July 2010 to April 2013). The survey of ergonomic assessment was a secondary outcome measure of the study.

Twenty centers were enrolled. Each center performed only one of the four surgical approaches. Six centers performed nephrectomy using open surgery retroperitoneal approach (OS), six using transperitoneal standard laparoscopy (SL), three using transperitoneal hand-assisted laparoscopy (HAL), and three using robot-assisted laparoscopy (RAL). Two centers that began implementing SL switched to RAL during the study. One or two surgeons performed all the nephrectomies at each center. Surgeons considered themselves experienced in all technical approaches used except RAL, where only 3 of the 5 surgeons considered themselves experienced.

The Borg CR-10 physical exertion scale ${ }^{8}$ was used to evaluate the physical exertion of surgery in 7 body parts over time, consisting of the neck, right shoulder and arm, left shoulder and arm, right forearm and wrist, left forearm and wrist, legs, and lower back. The surgeon and his assistant each completed this form every 30 mins during the procedure. The Borg CR-10 scale has rating levels ranging from 0 (rest), 0.5 (extremely easy), 1.0 (very, very easy), 2.0 (easy) to 10 (absolute maximum). ${ }^{9}$

Global workload was evaluated using the NASA Task Load Index (NASA-TLX). The NASA-TLX score rates a workload using subscales that evaluate mental demand, physical demand, temporal demand, overall performance, frustration level and effort. This tool has been validated in many work settings. ${ }^{10,11} \mathrm{~A}$ visual analogue score of 
nephrectomy difficulty for the surgeon was obtained at the end of the procedure using a score from 0 (very low) to 10 (very high) for each of these subscales.

This study was approved by the French Advisory Committee on Information Processing in Health Research (CCTIRS approved on July 26, 2012) and the National Commission on Informatics and Liberty (CNIL: DR-2010090). The trial was registered at clinicaltrials.gov (NCT02830568 on June 10, 2010). This study was registered with the French High Court. Patients undergoing renal transplants were approved and registered by the French BioMedicine Agency. All participants provided written informed consent, and that this trial was conducted in accordance with the Declaration of Helsinki.

Data were analyzed using ANOVA and the Wilcoxon/ Kruskal-Wallis test for quantitative analysis and a $\chi^{2}$ test or Fischer exact test for qualitative analysis. Continuous variables were presented as the mean \pm standard deviation (SD).
Count data were expressed as a number and percentage. Statistical analyses were conducted with SAS 9.4, Cary, NC, USA.

\section{Results}

Two hundred and sixty-four patients underwent donor nephrectomy using OS $(\mathrm{n}=65)$, SL $(\mathrm{n}=65)$, HAL $(\mathrm{n}=$ $65)$ and RAL $(n=69)$. Data were obtained from the primary surgeon in 258 nephrectomies and from the assistant in 256. Figure 3 show inclusions by the different hospitals. An average operating time of $202.7 \pm 63.5$ mins was noted in RAL, this value is significantly $(\mathrm{p}<0.0001)$ higher than in the other techniques (HAL, $157.5 \pm 44.2$ mins; SL, $173.6 \pm$ 49.8 mins; OS, $182.8 \pm 56.3 \mathrm{mins})$.

Surgeons performing RAL stood for a shorter time span than those performing other procedures RAL $(\mathrm{n}=69 ; 46.3 \pm$ 19.3 mins), HAL ( $\mathrm{n}=65 ; 118.2 \pm 33.0 \mathrm{mins}), \mathrm{SL}(\mathrm{n}=65$; $146.0 \pm 50.0$ mins $),$ OS $(\mathrm{n}=65 ; 134.8 \pm 47.6$ mins $)$

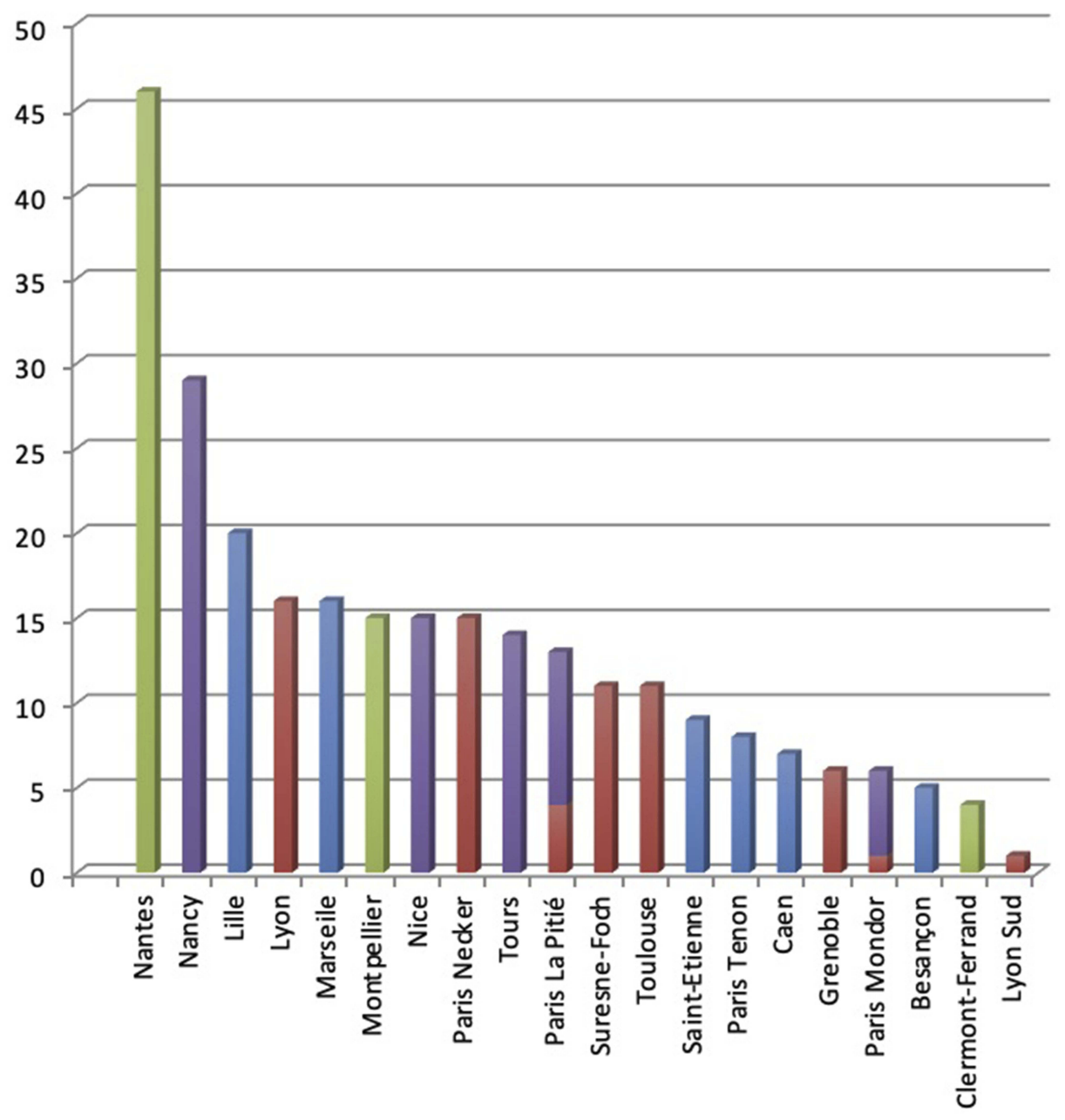

nobot assisted laparoscopy - Hand assisted laparoscopy - Standard laparoscopy - Open surgery

Figure 3 Inclusions by the different center. 
$(p<0.0001)$ and consequently sat for longer periods of time than those performing other procedures RAL $(n=69 ; 142.0 \pm$ 55.5 mins $), \operatorname{HAL}(n=65 ; 1.769 \pm 7.9 \mathrm{mins}), \operatorname{SL}(\mathrm{n}=65 ; 0.516$ \pm 2.3 mins $)$, OS $(n=65 ; 4.254 \pm 10.3$ mins $)(p<0.001)$.

\section{Borg CR-I0 Scale - Surgeon}

There was no difference in neck exertion by surgical approach over time for each of the 4 surgical approaches. Although most of the scores were in an easy range, RAL appeared to be less demanding for the left shoulder/arm of the surgeon as there were significant differences from 150 mins until 240 mins of surgery $(150 \mathrm{mins}$, Borg RAL $=0.1$ $\pm 0.4, \mathrm{p}=0.0072 ; 180$ mins, Borg RAL $=0.1 \pm 0.2 \mathrm{p}=$ $0.0005 ; 210$ mins, $0.1 \pm 0.5, \mathrm{p}=0.0041 ; 240$ mins, Borg $\mathrm{RAL}=0 \pm 0, \mathrm{p}=0.0293$ ).

Evaluation of the left forearm/hand demonstrated significantly lower stresses with the RAL approach from 30 to 150 mins (30mins, Borg RAL $=0.0 \pm 0.1, \mathrm{p}=0.0046$; 60mins, Borg RAL $=0 \pm 0.1, \mathrm{p}<0.0001 ; 90$ mins, Borg $\mathrm{RAL}=0 \pm 0.1, \mathrm{p}<0.0001 ; 120 \mathrm{mins}$, Borg RAL $=0 \pm 0.2$, $\mathrm{p}<0.0001 ; 150 \mathrm{mins}$, Borg RAL $=0 \pm 0.2, \mathrm{p}=0.0008$ ).

Evaluation of the right shoulder/arm demonstrated significant differences at 150 and 210 mins (150mins, Borg $\mathrm{RAL}=0.2 \pm 0.6, \mathrm{p}=0.0363 ; 210 \mathrm{mins}$, Borg $\mathrm{RAL}=0 \pm 0$, $\mathrm{p}=0.0111)$. There was no difference in the right forearm/ hand exertion scores by surgical procedure.

Lower back exertion was significantly greater with RAL than with other surgical approaches ( 0 mins, Borg $\mathrm{RAL}=0.5 \pm 0.9, \mathrm{p}<0.0001 ; 30 \mathrm{mins}$, Borg RAL $=0.4 \pm$ $0.8, \mathrm{p}=0.0113 ;$ 60mins, Borg $\mathrm{RAL}=0.7 \pm 0.8$, $\mathrm{p}<0.0001 ; 90 \mathrm{mins}$, Borg RAL $=0.9 \pm 0.9, \mathrm{p}<0.0001$; 120 mins, Borg RAL $=0.9 \pm 0.9, \mathrm{p}<0.0001 ; 150$ mins, Borg RAL $=1.1 \pm 0.9, \mathrm{p}=0.0001 ; 180$ mins, Borg RAL $=$ $1.1 \pm 1.1, \mathrm{p}=0.0108)$.

Leg exertion was significantly greater with OS than with other surgical approaches (150mins, Borg OS $=0.4$ $\pm 0.7, \mathrm{p}=0.0037$; 180mins, Borg OS $=0.8 \pm 1.1$, $\mathrm{p}=0.0037 ; 210 \mathrm{mins}$, Borg OS $=0.6 \pm 1.1, \mathrm{p}=0.0226$ ).

\section{Borg CR-I0 Scale - Assistant}

The surgeon's assistant experienced greater neck exertion at 120 and 150 mins during RAL, as indicated by Borg scale (120 mins, Borg $\mathrm{RAL}=0.5 \pm 1.0, \mathrm{p}=0.0034$; 150mins, Borg RAL $=0.7 \pm 1.3, \mathrm{p}=0.0053$ ).

The only difference in Borg score seen in the left arm and shoulder of the assistant was at 150 mins with RAL nephrectomy (150mins, Borg RAL = $0.5 \pm 0.9$, $\mathrm{p}=0.0417)$. Left forearm and hand exertion were greater with HAL at 60 and 210 mins, as determined by Borg scale (60mins, Borg HAL $=0.5 \pm 0.8, \mathrm{p}=0.0250 ; 210$ mins, Borg HAL $=0.8 \pm 1.6, \mathrm{p}=0.0385)$ and at $150 \mathrm{mins}$ with RAL (150 mins, Borg RAL $=0.4 \pm 0.8, \mathrm{p}=0.0194)$. Increased right shoulder and arm exertion were observed from 60 to 150 mins with RAL nephrectomy (60mins, Borg RAL $=0.6 \pm 1.0, \mathrm{p}=0.0018$; 90min, Borg RAL $=$ $0.6 \pm 1.0, \mathrm{p}=0.0012 ; 120 \mathrm{mins}$, Borg RAL $=0.8 \pm 1.1$, $\mathrm{p}<0.0001 ; 150$ mins, Borg RAL $=0.7 \pm 1.2, \mathrm{p}=0.0398)$.

Similar scores were seen between surgical groups at all other time points. Right forearm and hand exertion was consistently higher with RAL from 30 to 150 mins (30mins, Borg RAL $=0.2 \pm 0.4, p=0.0089$; 60mins, Borg RAL $=0.6 \pm 1.2, \mathrm{p}=0.0035$; 90mins, Borg RAL = $0.5 \pm 1.0, \mathrm{p}=0.0007 ; 120 \mathrm{mins}$, Borg $\mathrm{RAL}=0.7 \pm 1.2$, $\mathrm{p}=0.0021 ; 150$ mins, Borg RAL $=0.7 \pm 1.2, \mathrm{p}=0.0047$ ).

RAL was consistently associated with greater lower back exertion from 60 to 150 mins (60 mins, Borg $\mathrm{RAL}=0.7 \pm 1.0, \mathrm{p}=0.0087$; 90mins, Borg RAL $=1.0$ $\pm 1.1, \mathrm{p}=0.0001 ; 120$ mins, Borg RAL $=1.1 \pm 1.2$, $\mathrm{p}=0.0002 ; 150$ mins, Borg $\mathrm{RAL}=1.1 \pm 1.4$, $\mathrm{p}=0.0002)$. Greater leg exertion was observed with OS at 150 and $180 \mathrm{mins}(150 \mathrm{mins}$, Borg OS $=0.8 \pm 1.3$, $\mathrm{p}=0.0004 ; 180 \mathrm{mins}$, Borg OS $=0.8 \pm 1.3, \mathrm{p}=0.0017$ ).

\section{NASA-TLX Score - Surgeon}

Differences in NASA-TLX scores were observed for the 4 operative approaches in all 6 subscales (Figure 4). Global workload was lowest with the HAL approach and highest with RAL (RAL, $73.9 \pm 15.0$; HAL $48.3 \pm 24.4$; SL, $65.3 \pm$ 20.1; OS, $72.1 \pm 20.6 ; p<0.0001)$. Physical demand was the lowest with RAL (RAL, $41.8 \pm 16.4$; HAL, $53.2 \pm 28.2$; SL, $52.3 \pm 23.6 ; \mathrm{OS}, 54.6 \pm 25.4 ; p=0.0085)$. Mental activity was the greatest with OS (RAL, 73.2 \pm 15.3 ; HAL, $70.8 \pm 22.0$; SL, $52.3 \pm 23.6$; OS, $83.8 \pm 11.4 ; p<0.0001)$. Time constraint was greatest with RAL (RAL, $41.5 \pm 16.7$; HAL, $12.3 \pm 14.8$; SL, $39.7 \pm 22.4$; OS, $43.8 \pm 25.1$; $p<0.0001)$. Personal performance was greatest with RAL (RAL, $28.9 \pm 27.7$; HAL, $9.14 \pm$ 10.9; SL, 17.5 \pm 16.2 ; OS, $23.4 \pm 18.0 ; p<0.0001)$. The feeling of frustration was the greatest with RAL (RAL, $29.7 \pm 21.3$; HAL, $10.3 \pm 14.8 ;$ SL, $23.6 \pm 17.4$; OS, $22.9 \pm 20.2$; $p<0.0001)$.

\section{Discussion}

The use of laparoscopic and robotic techniques is increasing, and with it, the potential for surgically induced musculoskeletal disease in the surgical team. There are few studies evaluating the efficiency and comfort of the working environment of 


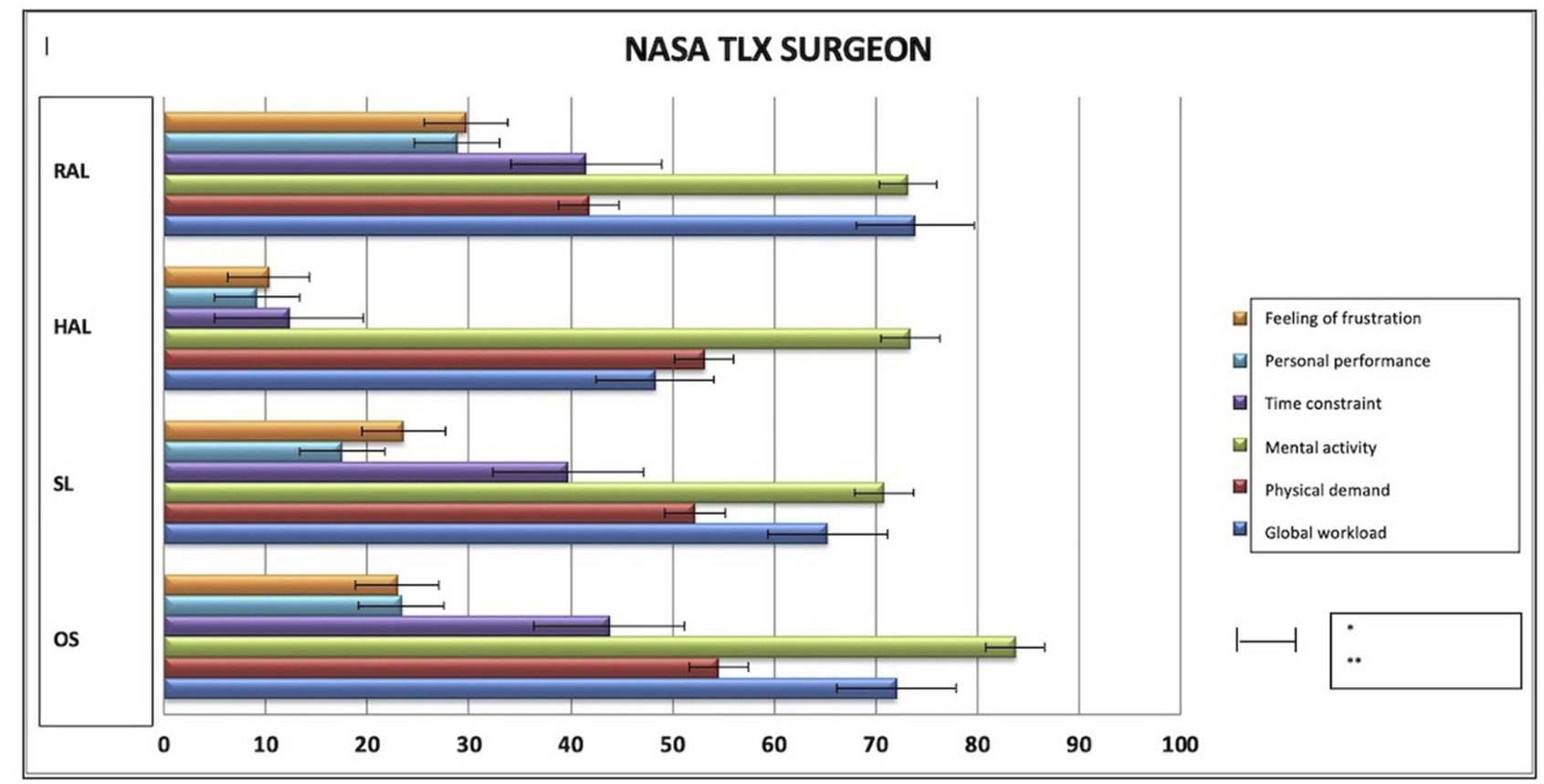

\pm SD

* Kruskal Wallis Test

Figure 4 NASA-TLX surgeon.

surgeons. We evaluated the ergonomic features and mental constraints during 4 operative approaches for nephrectomy using the Borg CR-10 scale and NASA TLX scores. Findings for the surgeon and their assistant were evaluated.

Our RAL operative times were significantly longer than those with HAL, SL, and OS, comparable with previous reports. ${ }^{11}$ Fatigue associated with lengthy operative time is one factor that could contribute to these longer times.

HAL was associated with worse scores after 2 hrs in both shoulders and arms, apparently due to fatigue related to bending over the hand port. Similar findings have been reported for the upper limbs with other surgical procedures. $^{12}$ Experience with RAL could also explain some of the longer operating times, as the average RAL operating time in the center with the greatest experience was 160.3 mins, similar to other procedure times.

Borg exertion scores for all body parts generally ranged from 0 (rest) to 0.5 (extremely easy). Scores in the 1.0 to 2.0 (easy) range were occasionally found after $3 \mathrm{hrs}$ of surgery. In these conditions, the perceived exertion being less than 2 on the BORG CR10 scale, this reflects a weak physical exertion. It is now accepted that work-related musculoskeletal disorders could appear even with weak physical exertion since other individual, organizational and biomechanical factors may come into play. ${ }^{12}$
Surgeon Borg scores for the legs generally decreased from HAL to OS to SL to RAL for most of the operative times evaluated. Similar findings have been reported for the legs with other surgical procedures. ${ }^{13}$

The generally higher surgeon Borg scores with RAL in the lower back were attributed to the strain of leaning forward in the sitting position at the robotic controls with the head tilted down at the viewing binocular. The decreasing scores at the end of the procedure were attributed to times when the surgeon was standing again and in better posture while removing the robotic device and closing port sites. Guidelines for microscope use have been extended to benefit RAL workers and should be implemented. ${ }^{14}$ These guidelines call for a neutral vertical position at the console, minimizing neck and back strain.

Assistant Borg scores for the right shoulder and arm and right forearm and hand were higher with RAL from 60 to 150 mins. This is the peak of RAL work time, after the robot is positioned for work, when the assistant must work around the robotic device, and when fatigue can begin to set in. No consistent differences in leg score were observed early in the different procedures, while later on OS was more consistently associated with higher assistant leg scores. Ergonomics evaluation of a surgical assistant has not been previously reported. 
A proportional relationship has been reported between the intensity of the discomfort felt and the difficulty of the task and the physiological stress experienced. ${ }^{8,15}$ The NASA-TLX was used to assess the surgeon's perceived workload during each operative procedure, ranging from 0 to 100 . Mental demand was significantly higher during OS. Physical demand scored lower, in the 40 to 50 range, with the lowest scores associated with RAL.

Temporal demand evaluated the time pressure felt by the surgeon, with RAL being the most demanding. This finding may be related to the slightly longer surgical time found in robotic surgery. This time difference may be attributed to the lack of experience in 2 out 5 surgeons and the time required to dock the robot to the patient. This time has been estimated as about 20.5 mins with the da Vinci SI robot. ${ }^{16}$ Personal performance scores were low for all surgical approaches examined. The best scores were seen with RAL. Overall workload of the procedure by the surgeon ranged from approximately 50 to 75 . The best scores were achieved using HAL and the worst with RAL.

The appearance dynamics of work-related musculoskeletal disorders combine in the same time biomechanics factors (force, repetitiveness, postures) with psychosocial work factors (long hours at work, work content, high job demands, low control/influence, lack of social support) and organizational and individual factors (age, genre, experience, etc.). All these factors interact together to accentuate the biomechanical constraints. In this study, some of psychosocial work factors were evaluated with NASA-TLX score and seem to disrupt the work of surgeons, whatever the kind of surgery. This is particularly the case for the mental activity and the global workload. On the other hand, feeling of frustration and personal performance are less expressed in groups containing experienced surgeons (OS, HAL and SL groups) than in groups containing more novices ones (two surgeons are novice in RAL group).

Seventy percent of HAL nephrectomies were performed at one center, by one surgeon, which should contribute to good feelings of surgeon adequacy, but may bias scores toward those originating at that institution.

Some observational study of 1407 surgeons of all specialties reported physical discomfort in $55.4 \%$ of operators performing laparoscopic surgery, $36.3 \%$ of those performing open surgery, and only $8.3 \%$ of those performing robotic surgery. ${ }^{17}$ These findings may be explained by electromyographic studies of surgeons performing in SL and RAL that demonstrated lesser muscular work, mainly in the trapezius, deltoids, triceps, and biceps muscles in
RAL, compared to SL. ${ }^{18,19}$ The frequency of physical discomfort reported in the literature paralleled the intensity of the surgical experience, as measured with Borg and NASATLX scores, in our surgeons and surgical assistants.

RAL appears particularly difficult physically for the surgical assistant. The presence of the slave carriage and the arms of the robot cause significant congestion in the surgical environment and the assistant can be forced to work in awkward positions, with outstretched arms or leaning, to work around the robot. The table height cannot be adjusted once the robot is docked, which also may require leaning or twisting in awkward positions for extended periods of time. This position can add a physical burden to the neck, shoulders, and back. ${ }^{20,21}$ Optimal screen positioning is at eye level, facing the operator. Robot placement can often require screen placement outside the ideal location. ${ }^{22,23}$

There were several limitations to this study. Surgeon and assistant age, height, weight, right or left-handed and medical history were not available. Obese individuals or those with musculoskeletal disease could have been predisposed to worse ergonomic-related scores. Differences in surgical experience with each technique could also have affected scoring with RAL. We did not report data about the patients such as the number of renal arteries or surgical history this could influence the level of difficulty, the procedure length and the level of stress of the surgical team. This could bias our results.

The relative amount of ergonomics training and the surgical knowledge of different surgeons and their assistants were not known. This could have a major effect on scoring as evidence by an ergonomic training program for American gynecological surgeons that resulted in a $74 \%$ reduction in physical complaints among participants. ${ }^{24}$ Hardware development such as new generation of surgical robot or new ergonomic-specific chair ${ }^{25}$ should improve exertion score for the surgeons.

\section{Conclusion}

For surgical patients, the benefits of laparoscopic minimally invasive techniques are well established. These techniques have, however, degraded the working conditions of surgeons. This showed that surgeon and assistant scores of physical exertion were generally in the "easy" range but confirmed that robotic surgery is an ergonomic progress compared to other techniques, except for the axial skeleton. On the other hand, it degrades the working conditions for the assistant. Surgeons and their assistants should be aware of ergonomic problems and plan to minimize positional problems during surgery. 


\section{Abbreviations}

HAL, hand-assisted laparoscopy; NASA-TLX, national aeronautics and space administration task load index; OS, open surgery; RAL, robot-assisted laparoscopy; SL, standard laparoscopy.

\section{Data Sharing}

The authors will share global Nasa TLX and Borg scale data but will not share individual deidentified participant data. If you want to access those data please mail us at b.marcon@chru-nancy.fr and I will send the files needed. Those data will be accessible for 1 year after publication.

\section{Ethics Approval And Informed Consent}

This study was approved by the French Advisory Committee on Information Processing in Health Research (CCTIRS approved on July 26, 2012) and the National Commission on Informatics and Liberty (CNIL: DR-2010090). The trial was registered at clinicaltrials.gov (NCT02830568 on June 10, 2010). This study was registered with the French High Court. Patients undergoing renal transplants were approved and registered by the French BioMedicine Agency.

\section{Acknowledgments}

The study was coordinated by INSERM CIC-EC 1433 at Nancy University Hospital and involved 20 centers in France. We thank all the investigators for their investment in the project. This project was funded by the French Ministry of Health (DHOS STIC 2009). Opinions expressed in the present article are those of the authors and do not necessarily reflect those of the sponsor. The study sponsor did not take part in the study design, collection, analysis and interpretation of data, writing of the report or decision to submit the article for publication.

\section{Disclosure}

The authors report no conflicts of interest in this work.

\section{References}

1. Hemal AK, Srinivas M, Charles AR. Ergonomic problems associated with laparoscopy. J Endourol Endourol Soc. 2001;15(5):499-503. doi:10.1089/089277901750299294

2. Berguer R, Chen J, Smith WD. A comparison of the physical effort required for laparoscopic and open surgical techniques. Arch Surg Chic Ill 1960. 2003;138(9):967-970.
3. Miller K, Benden M, Pickens A, Shipp E, Zheng Q. Ergonomics principles associated with laparoscopic surgeon injury/illness. Hum Factors. 2012;54(6):1087-1092. doi:10.1177/001872081245 1046

4. Bagrodia A, Raman JD. Ergonomics considerations of radical prostatectomy: physician perspective of open, laparoscopic, and robotassisted techniques. J Endourol Endourol Soc. 2009;23(4):627-633. doi:10.1089/end.2008.0556

5. Lee GI, Lee MR, Green I, Allaf M, Marohn MR. Surgeons' physical discomfort and symptoms during robotic surgery: a comprehensive ergonomic survey study. Surg Endosc. 2017;31(4):1697-1706. doi:10.1007/s00464-016-5054-z

6. Sgarbura O, Vasilescu C. The decisive role of the patient-side surgeon in robotic surgery. Surg Endosc. 2010;24(12):3149-3155. doi:10.1007/s00464-009-0795-6

7. Park A, Lee G, Seagull FJ, Meenaghan N, Dexter D. Patients benefit while surgeons suffer: an impending epidemic. $J$ Am Coll Surg. 2010;210(3):306-313. doi:10.1016/j.jamcollsurg.2009.10.017

8. Borg G. Borg's Perceived Exertion and Pain Scales. Vol. viii. Champaign, IL: Human Kinetics; 1998:104.

9. Borg GA. Psychophysical bases of perceived exertion. Med Sci Sports Exerc. 1982;14(5):377-381. doi:10.1249/00005768-1982050 00-00012

10. Young G, Zavelina L, Hooper V. Assessment of workload using NASA Task Load Index in perianesthesia nursing. J Perianesthesia Nurs off J Am Soc Perianesthesia Nurses. 2008;23(2):102-110. doi:10.1016/j.jopan.2008.01.008

11. Ruiz-Rabelo JF, Navarro-Rodriguez E, Di-Stasi LL, et al. Validation of the NASA-TLX score in ongoing assessment of mental workload during a laparoscopic learning curve in bariatric surgery. Obes Surg. 2015;25(12):2451-2456. doi:10.1007/s11695015-1922-1

12. Descatha A, Roquelaure Y, Evanoff B, et al. Selected questions on biomechanical exposures for surveillance of upper-limb work-related musculoskeletal disorders. Int Arch Occup Environ Health. 2007;81 (1):1-8. doi:10.1007/s00420-007-0180-5

13. Tarr ME, Brancato SJ, Cunkelman JA, Polcari A, Nutter B, Kenton $\mathrm{K}$. Comparison of postural ergonomics between laparoscopic and robotic sacrocolpopexy: a pilot study. J Minim Invasive Gynecol. 2015;22(2):234-238. doi:10.1016/j.jmig.2014.10.004

14. Lux MM, Marshall M, Erturk E, Joseph JV. Ergonomic evaluation and guidelines for use of the daVinci Robot system. $J$ Endourol. 2010;24(3):371-375. doi:10.1089/end.2009.0197

15. Borg G. Psychophysical scaling with applications in physical work and the perception of exertion. Scand J Work Environ Health. 1990;16:55-58. doi:10.5271/sjweh.1815

16. Abdel Raheem A, Sheikh A, Kim DK, et al. Da Vinci Xi and Si platforms have equivalent perioperative outcomes during robotassisted partial nephrectomy: preliminary experience. J Robot Surg. 2017;11(1):53-61. doi:10.1007/s11701-016-0612-x

17. Plerhoples TA, Hernandez-Boussard T, Wren SM. The aching surgeon: a survey of physical discomfort and symptoms following open, laparoscopic, and robotic surgery. J Robot Surg. 2012;6(1):65-72. doi:10.1007/s11701-011-0330-3

18. Zihni AM, Ohu I, Cavallo JA, Cho S, Awad MM. Ergonomic analysis of robot-assisted and traditional laparoscopic procedures. Surg Endosc. 2014;28(12):3379-3384. doi:10.1007/s00464-0133343-3

19. Hubert N, Gilles M, Desbrosses K, Meyer JP, Felblinger J, Hubert J. Ergonomic assessment of the surgeon's physical workload during standard and robotic assisted laparoscopic procedures. Int $J$ Med Robot Comput Assist Surg MRCAS. 2013;9(2):142-147. doi:10.10 $02 /$ rcs. 1489

20. Berquer R, Smith WD, Davis S. An ergonomic study of the optimum operating table height for laparoscopic surgery. Surg Endosc. 2002;16 (3):416-421. doi:10.1007/s00464-001-8190-y 
21. Matern U, Waller P, Giebmeyer C, Rückauer KD, Farthmann EH. Ergonomics: requirements for adjusting the height of laparoscopic operating tables. JSLS. 2001;5(1):7-12.

22. Matern U, Faist M, Kehl K, Giebmeyer C, Buess G. Monitor position in laparoscopic surgery. Surg Endosc. 2005;19(3):436-440. doi:10. 1007/s00464-004-9030-7

23. Zehetner J, Kaltenbacher A, Wayand W, Shamiyeh A. Screen height as an ergonomic factor in laparoscopic surgery. Surg Endosc. 2006;20 (1):139-141. doi:10.1007/s00464-005-0251-1
24. Franasiak J, Craven R, Mosaly P, Gehrig PA. Feasibility and acceptance of a robotic surgery ergonomic training program. JSLS. 2014;18 (4). doi:10.4293/JSLS.2014.00325

25. Dalager T, Jensen PT, Winther TS, et al. Surgeons' muscle load during robotic-assisted laparoscopy performed with a regular office chair and the preferred of two ergonomic chairs: a pilot study. Appl Ergon. 2019;78:286-292. doi:10.1016/j.apergo.2018.03.016

\section{Publish your work in this journal}

Research and Reports in Urology is an international, peer-reviewed, open access journal publishing original research, reports, editorials, reviews and commentaries on all aspects of adult and pediatric urology in the clinic and laboratory including the following topics: Pathology, pathophysiology of urological disease; Investigation and

Submit your manuscript here: https://www.dovepress.com/research-and-reports-in-urology-journal treatment of urological disease; Pharmacology of drugs used for the treatment of urological disease. The manuscript management system is completely online and includes a very quick and fair peer-review system, which is all easy to use. Visit http://www.dovepress.com/ testimonials.php to read real quotes from published authors. 